\title{
An Introduction to the HLanData Project: a Step Forward in the Harmonization of Spatial Information throughout Europe
}

\author{
Sarmite Barvika \\ Riga Technical University \\ The Faculty of Engineering Economics and Management \\ Riga, Latvia \\ sarmite.barvika@rtu.lv
}

\author{
Liga Jankava \\ University of Latvia \\ Faculty of Geography and Earth Sciences \\ Riga, Latvia \\ ljankava@gmail.com
}

Received: January 17, 2019. Revised: March 20, 2021. Accepted: October 3, 2021. Published: November 16, 2021.

\begin{abstract}
Nowadays spatial information is becoming more and more accessible for various purposes due to local, national and European initiatives. This paper is addressed to one such initiative Hlandata, whose purpose is to make a significant step forward in the harmonization and use of land cover (LC) and land use (LU) geographic data and its related data bases over Europe. The project was developed using the best experiences from previous geographic data harmonization activities with the goal of demonstrating the feasibility of European level harmonization of land information related datasets. The three pilot projects "LU-LC Data Analysis System for intermediatelevel users", "Harmonized and Interoperable Land Information Systems" and "Stratification of Waste Dumps" were developed and tested within the project and demonstrated advantages from user oriented value-added services emphasizing data search, exploration and analysis.
\end{abstract}

Keywords-land use: land cover; GIS; INSPIRE

\section{THE IMPORTANCE OF LAND COVER AND LAND USE INFORMATION}

Nowadays LC and LU information is amongst the most requested geographic data because of its essentiality of use and application in various areas (environmental impact evaluation, Global Monitoring for Environment and Security (GMES) application, evaluation-projection on water consumption, study on habitats and ecosystems, calculations on erosive states, study and evaluation of town-planning growth models, etc.) and is fundamental in performing planning in a sustainable manner. The ability of information technologies to handle geographic data has improved during the past two decades and Geographic Information Systems (GIS) are well suited to the integration and management of local, national and international land, natural resources and property related data. Particularly various sectors of "property industry" represent significant market potential for GIS, especially in the use and processing of LC and LU geographic data for commercial and non-commercial purposes. [8] [16] LC represents the biophysical state of real landscape (natural, human modified and artificial objects on land surfaces). LU reflects the social-economic purpose for which land is used (current and perspective land for residential, industrial, commercial, agricultural etc. purposes). Together, these two data sets provide complementary information for the particular territory both in landscape and development potential. [2]

\section{EFFORTS IN HARMONIZING SPATIAL DATA}

The history of use of land is very relevant to planning function. [16] For a long time LC and LC information has been stored and managed separately at different levels: European, national, or local, without application of the systemic approach, common standards and classification. Past activities producing land related information from the local to the European level have been mostly developed independently, addressing the specific requirements of the information (scale, accuracy, resolution, data acquiring, update period, etc.) or user (public and private sector, individuals etc.). This has resulted in numerous datasets, mainly neither compatible with each other nor taking into account the interoperability of accumulated information. [2] [5] [4] However in the context of monitoring environmental changes (loss of biodiversity, climate changes, food safety etc.), harmonization activities have increasingly touched global issues with regard to better integration of various sources of information on various scales (for example: the European CORINE LC Initiative is integrated into the initial GMES programme framework). [9] [10] [13] [15]

$$
\text { ,,, ஐ0 2' ( } 51 \text { प+\$5021, =\$7,21 प( )) } 2576
$$

Globalization is affecting spatial planning, requiring new ways of governance to take advantage of its benefits, while data collection requires new approaches in the way of data collection and use within a sustainable local and cross-border context. The main European spatial information harmonization initiative, the INSPIRE directive (2007), established general rules for the implementation of thirty four spatial data sets, including LC and LU related information, (Annexes I, II and III of the directive) in entire European Community to support Community's policies regarding fulfillment of the requirements of environmental issues around Europe. [8] [6] 
[12] The implementation of this directive should be based on the previously developed spatial data infrastructures of Member States and does not require new data collection system. The Member States must ensure that this infrastructure is compatible, interoperable and usable on the national level, as well as in the Community trans-boundary context. [10] Currently INSPIRE directive is also a key driver for the standardization and harmonization of LC and LU information in the European Union (EU), but there is still a long process to reach a satisfactory outcome due to different standards and practices of Member States. At the same time, the INSPIRE implementation measures (EU initiatives, project activities, best practices) have been regularly tested, identified and supported by the INSPIRE Technical Working Group (TGW) to provide the best experience available on LC and LU mapping in Europe for the purpose of insuring the successful implementation of the INSPIRE objectives. Close cooperation with INSPIRE TWG was also one of the achievements of the HLanData project in regard to the outcomes of the project activities regarding the development of the perspective data categorization and data model. [4]

\section{THE HLANDATA APPROACH}

The HLanData project is one of recently completed European projects (with a 36 months duration, which ended in February, 2013) and is relevant to the expected target outcomes listed in the ICT PSP 2009 Work Programme. [11]

Nowadays LC and LU information in European countries has been managed at national, regional or local level, which resulted in a suite of datasets, not always standardized, compatible with each other. But in a context where environmental threats (such as climate change, biodiversity loss and food security) become more and more global, there is a need to better integrate various sources of information at various scales. Therefore this European project's aim was to widen the use of LC and LU spatial data by the public and private sector, organizations and citizens through the development of some user oriented value-added services The HLanData brought together nine partners with relevant GIS oriented project experience from seven European countries (Spain, the Netherlands, Czech Republic, Slovak Republic, Austria, Latvia and Lithuania), but lead by the Government of Navarre and TRACASA (Spain). The project was built on experiences of previous harmonization activities and their best practices in close cooperation with INSPIRE TWGs, aiming to demonstrate cooperation among the feasible European level harmonization of the land information related datasets taking into account both data categorization and models through the development of user oriented value-added web-services to streamline harmonized data exploration and analysis. [4] Target users of the proposed services are LC and LU information users at European, national and local level.

The specific objectives of the HLanData project were:

- $\quad$ to contribute to the common (European) data sharing infrastructure;
- to test INSPIRE TWGs data specification to assure sharing land cover and land use data between different public authorities and other stakeholders at the local, regional, national and European level;

- $\quad$ to promote the use of LC and LU spatial data at the European level through the developed value-added web-services in the various pilot projects;

- to make available to the public the project's results using dissemination activities with respect to deliverables and outcomes (pilot projects) [4].

\section{A. Project Work Plan and Its Implementation Activities}

The HLanData project activities consisted of four work packages: WP1 "Diagnostic", WP2 "Harmonization of LC/LU data and development of the baseline LU/LC sharing infrastructure", WP3 "Pilots design and implementation" and WP4 "Results assessment" (see Fig. 1). [2] [4]

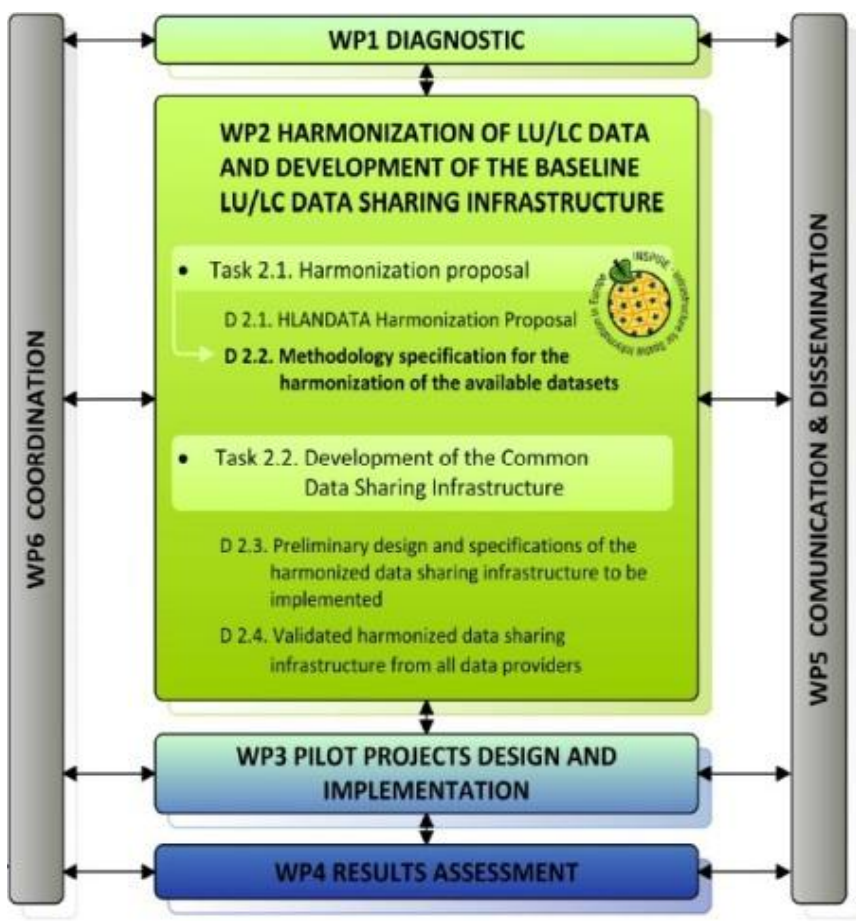

Fig. 1. HLanData work plan

However, the practical implementation of the project was split into three main phases: "Diagnostic phase", "Harmonization and development of common data infrastructure phase" and "Value-added web services implementation and validation. The "Diagnostic phase" considered the assessment of current European stage (situation) regarding the harmonization of LC and LU geographic information, taking into account ongoing initiatives regarding the data categorization and modeling (for example: SIONE, LISA), as well as assessing the needs of end users from point of view of data harmonization and functionality in high-level spatial data services developed by 
the project. The outcome from the second phase "Harmonization and development of common data infrastructure phase" - was based on the diagnostic results. The developed harmonization proposal for LC and LU geographic data was provided to respective TWG, both from the perspective of the data categorization and the data model. [4] Within this phase the common data sharing infrastructure (CDSI), HLanData geoportal, was also developed to support harmonized LC and LU data storage and maintenance in different sources across Europe. [2] [4] HLanData geoportal is the access portal to the CDSI and harmonized WMS and follows the principle: one centralized access to decentralized data.The HLanData Geoportal has the following basic functionalities: viewing, discovering and map creation. Currently the HLanData geoportal provides a map viewer to overlay and compare spatial data and metadata catalogue that allows searching of available data from participants' countries. The architectural design of the portal consists of "three tier" architecture, which has the advantages of flexibility, good scalability and thin clients. [4]. The project ended in the implementation of the third phase - "Value-added web services implementation and validation" - where the CDSI was used and data harmonization potential was tested by developing and using three specific value-added thematic web-based services (pilot projects)"..[2] [3] [4]. An important project activity was the testing of developed web-services through pilot projects, the project overall assessment, as well as the dissemination of the project. [3]

\section{B. The Pilot Projects}

The three specific value-added thematic web-based services (pilot projects) were developed and successfully tested as part of the HLanData project for selected users: Pilot 1 "LU/LC Data Analysis System for Intermediate-Level Users" (Spain), Pilot 2 "Harmonized and Interoperable Land Information Systems" (Check Republic, Lithuania) with two subpilots (2.1 "Harmonized Interoperable National Land Information Systems" and 2.2. "Establishment of a National Land Statistical Accounting System Based on GMES Core Mapping Service Products"); and Pilot 3 "Stratification of Waste Dumps" (Slovakia), (see Fig 2). [4]

\section{Services Starting Point}

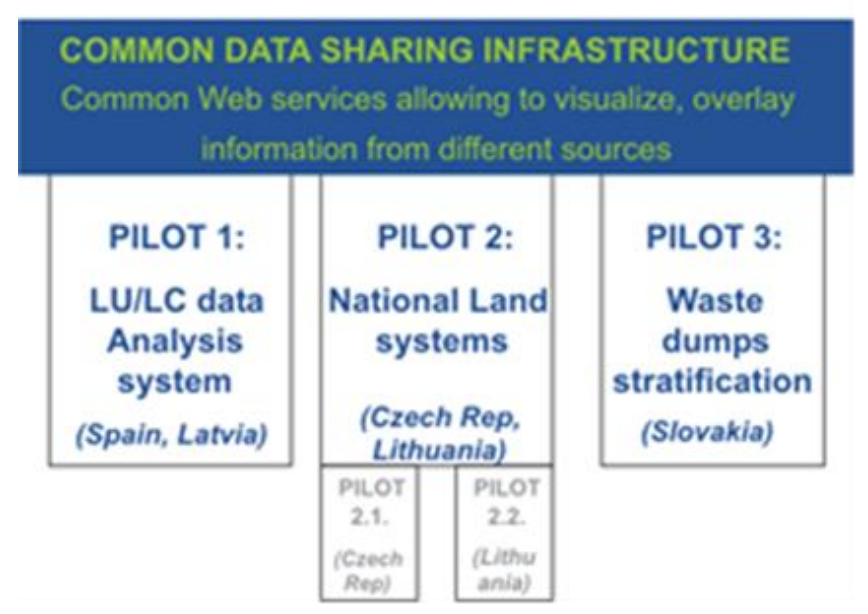

Fig. 2. HLanData pilots

The development of all pilots was based on the results from previous project phases. In order to achieve the objective, three main tasks were defined for the pilots: design of the pilot projects, development and the running of the pilot projects, and validation. The group of potential users for developed services was identified within the project.

The segmentation of all users of the LC and LU cartography within the HLanData project distinguishes between:

- Low-level users (or general public): They access LC and LU data through the spatial data infrastructures and use only the information layers overlaid on to an ortophoto map;

- Intermediate-level users: Technicians of the public administration at local, regional and national levels, services and networks administrators, public entities from different sectors (urban land, forest and rural environments), private companies, educational institutions, architects and engineers. Their needs include functionalities such as the visualization of the LC and LU layer, the overlay of their own information onto other sources, spatial and temporal analysis, and the downloading of data in different formats; [14]

- High-level users: Professionals who carry out highlevel analysis by making use of GIS tools. Possibly the services to be created are not sufficient for their needs, but they will be able to get LC and LU data layers through downloading applications in order to incorporate them to their GIS.

It should be recognized, that the rest of HLanData project outcome was oriented to the needs of "intermediate-level users" to promote the use and standardization of LU and LC related information that is maintained and used by public and private bodies. 
The functionality of the developed services in most of these cases is provided using standardized web-services (WMS, WFS, WPS), standardized IT protocols and formats (REST, JSON). The basic services are provided within each pilot project using specialized web-based map applications that allow users free access and the performing of selected operations to obtain requested new information using harmonized LC and LU data. The map layers of each pilot project include harmonized WMS, which were prepared in previous stages of the project. Both, Open Source and commercial development frameworks were tested in implementation of the pilot projects, but users comfort assessment was carried out within validation of the design of each pilot project. Due to data harmonization in accordance with common standards, the LU and LC data across Europe can be shown on the one map, with a common (standardized) legend, and therefore has become "a key issue" for crossborder planning and analysis activities. [4] [7] User comfort is provided by an interactive web-based approach: a fast and flexible environment which allows one to view and analyze user defined themes, web-tools that are strictly Open Source based, the free definition of analysis details and units (size of area), the saving of used files etc. [4] The pilot project also has contributed to the increasing use and reuse of harmonized data sets related to LC and LU themes from Annexes I-III of the INSPIRE directive through network services for sharing spatial data between public authorities and other stakeholders, enabling the creation of value added services. [4]

\section{Pilot 1: LC/LU Data Analysis System for Intermediate- Level Users}

This pilot project was developed mainly by two partners: Spain and Latvia. Gobierno de Navarra (Spain), IGN/CNIG (Spain) and TDF (Latvia) participated in the pilot as content providers and end users, but Tracasa (Spain) and CEIT Alanova (Austria) provided technology for this development. [2]

The Pilot 1 was addressed to the group of ,intermediate-level users" of LC and LU information and is a system (accessible on: https://gisportal.tracasa.es/hlandata/viewer/ ) that allows users to make advanced analysis (viewing, overlaying, spatial and temporal analysis, downloading, data maintenance etc.) of the LC and LU datasets with information coming from different sources (Navarre region, Spain and Latvia) at a European level. (see Fig. 3).

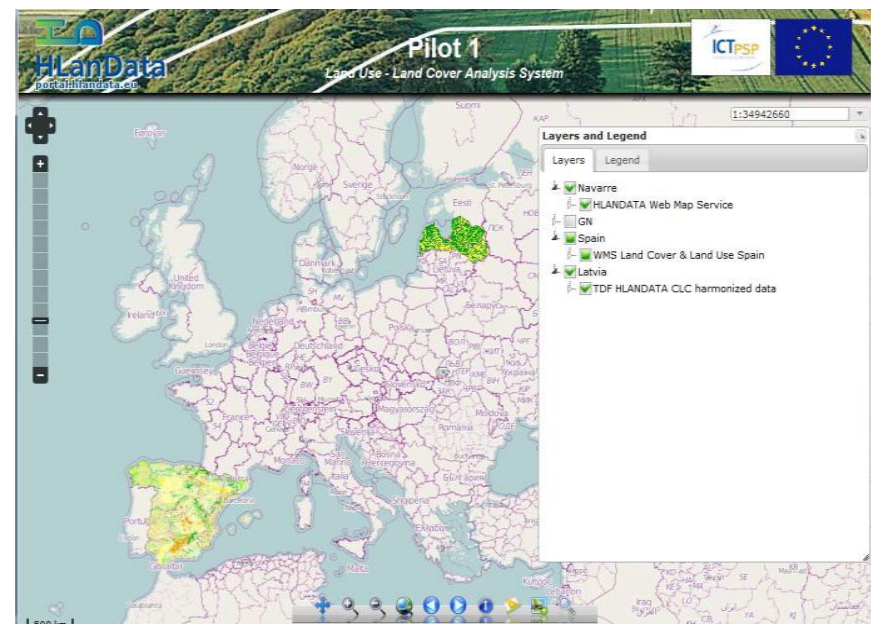

Fig. 3. HLanData Pilots $1-$ web tool interface

Proposed solution solved several earlier observed problems (or practices): such requests for $\mathrm{LU}$ and $\mathrm{LC}$ information in different formats (for example CAD), management of $\mathrm{LC}$ and LU information layers through desktop viewers had some limitations regarding its non-universal use (typical practice of local administration for management their own spatial data), etc. Thanks to this development, the new system allows one to process selected data (for example a selected area of a specific land parcel) together with other attributed data (for example descriptive data on a specific selected land area and related statistics on the territory), to download and print the obtained results; and to save used or created data files. In addition, the pilot project made this information available to a significantly bigger amount of users. [14]

\section{Pilot 2: Harmonized and Interoperable Land Information Systems}

The two subpilots were developed within the Pilot 2 "Harmonized and Interoperable Land Information Systems (LIS)": Subpilot 2.1 - Harmonized Interoperable National LIS (Czech Republic) and Subpilot 2.2 - Establishment of a National Land Statistical Accounting System Based on GMES Core Mapping Service Products (Lithuania) focusing on making the national LIS interoperable, standardized and a "user-friendly tool oriented" to explore, describe, compare and explain LC and LU changes in a socio-economic context. In order to achieve the level of flexibility and usefulness required by users, the service specification for the Pilot 2 went far beyond the traditional concept of data provision. [4] In the framework of the HLanData Subpilot 2.1, the Czech partner had excellent cooperation among three involved participants: GISAT and CENIA, which jointly serve as the National Reference Centre (EIONET NRC) for Spatial Analysis and Land Cover in the Czech Republic, work on exploring the potential for the setup of a national LIS within this HLanData framework. The Pilot 2.1 focused mainly on technical issues, but also reflected organizational support required in setting up a data sharing cycle between the national mandated actors and data providers of partial LC and 
LU data in a harmonized way. [4] It was observed that the demands in regard to LIS are similar in different countries and there is a strong need for harmonization of both core mapping services and downstream (added value services) activities so that the results with regard to content and service are comparable between the countries and also at the European level as is required by INSPIRE principles. In the Czech Republic, as in many other countries, LC and LU related information is collected and managed for special domains (forestry, water, agriculture etc.) by a number of different national organizations based on their mandate, specific management needs and requirements on data content and structure, as well as mapping scale. [4] At the same time all stakeholders (public and private bodies, decision makers, NGOs, researchers, planners, GIS analysts, the general public) require access to adequate and comprehensive spatial data to achieve their needs: interdisciplinary analysis and research; planning activities, transparency and participation in decision making, efficient integrated data management, monitoring of environmental changes, and safety and disaster management etc.

Inspired also by the European Environmental Agency the Land and Ecosystem Accounting framework [4], the Pilot 2 was based on an interactive web-based approach, where both spatial and socio-economical statistical data are delivered in an organized way, together with tools in a fast and flexible way [4]. Due to use of common data harmonization standards, the LC and LU data across Europe now can be shown together in single map on the HLanData geoportal. The developed common legend is a "key issue" for easy use of this data for the purpose of cross-border analysis and integrated planning activities. Supported by INSPIRE directive implementation activities in the Czech Republic and the progress in the GMES area, the pilot also demonstrated its practical implementation in LC/LU domain, allowing data sharing between the individual actors involved through network services. [4] Access to information concerning Pilot 2.1 is available at: http://hlandata.gisat.cz/appv2 .

Subpilot 2.2 "Establishment of a National Land Statistical Accounting System based on GMES Core Mapping Service (CMS) Products" was developed by our Lithuanian partner and is based on the current running implementation of the new Lithuanian concept of a national Statistical Land Accounting System (SLAS).

The main objective of Subpilot 2.2 was the practical implementation and operational testing of the SLAS on the basis of GMES CMS products based on the HLanData methodology for data harmonization. The Subpilot covered two trans-boundary river basins - Nemunèlis $(4,047 \mathrm{~km} 2)$ with its dominating natural landscapes and Mūša $(5,463 \mathrm{~km} 2)$ with an intensely agricultural landscape - both stretching along the area of northern Lithuania and southern Latvia. [4] The SLAS is basically used to keep information of the amounts of different national land assets (arable land, forests, built-up areas, etc.) for the purpose of planning budget assignments, incomes, agricultural quotas, as well as for spatial planning at the national and municipal level. The project survey focused attention on conceptual incapability in data structure of SLAS among the former "Soviet block" countries (now EU member states) and the "old member states". After accession to the EU (2004), old, inherited "Soviet time" statistical systems became almost inoperable due to:

- The implementation of numerous EU regulations relating to agriculture and the environment (Natura2000 network, water framework directive, directives on carbon emissions and climate change, etc.);

- Incomplete data and new requirements of stakeholders with regard to land data structure and statistics concerning rural and urban areas.

Therefore in Lithuania the new concept on national SLAS (formulated by State Land Service under the Ministry of Agriculture) was based on advanced GIS, remote sensing technologies and particularly on the emerging GMES CMS, developed within of the FP7 projects coordinated by EC in cooperation with EEA and ESA, as well as GMES Service Elements carried out by ESA member states, possibly developing additional GMES Downstream Services for specific thematic content particularly requested by national stakeholders. The feasibility study took place with regard summarizing the current situation, identifying information gaps and expectations of the major stakeholders, testing the existing spatial data properties, recent GMES technologies and practical issues related to production of high-resolution LU/LC datasets, as well as providing the necessary technical and thematic specifications and spatial data infrastructure requirements for the national SLAS [2] [4] After the implementation of the SLAS pilot project (Subpilot 2.2), the State Land Service of Lithuania also launched a regular monitoring program and incorporated the high-resolution LU/LC datasets and statistical land accounting products into the recently established Lithuanian Spatial Information. [4] More information about Pilot 2.2 is available at: http://hlandata.agi.lt/ .

\section{E. Pilot 3: Stratification of Waste Dumps}

The main objective of Pilot 3 was the stratification and control of waste dumps in Slovakia through an interactive mapping service including the following geographic information layers: LC and LU, settlements, population and waste production. Problem of waste production and dump localization is complex and often causes conflicts in many countries and now it is global problem. For example in Slovakia long-term waste disposal in landfills is still the most frequent method of municipal waste handling ( $76 \%$ ) despite the efforts to decrease the number of official landfills in regard to national and European law. Therefore a public map service would be very helpful in overcoming discrepancies between government, the industrial sector, environmental communities and the public. An interactive map service would also be helpful in the process of mapping existing official dumps, forbidden dumps and for proposals of new dumps based on LC and LU multitemporal GIS dataset (the key layers like 
population, waste production, LC/LU, hydrology and environment protection).

The services of Pilot 3 focused on crucial GIS functionalities, which are necessary for the main potential user of this service - the general public, local and international decision makers and waste managers. For example, the potential user may help in the mapping of forbidden waste dumps by GPS localization or by simple editing of the positions thanks to othophoto or civil maps in the background. The system also enables the general public and institutional bodies to check the status of dumps, put them under control, discuss solutions with local regional governmental bodies and municipalities, overlay available transport layers and propose forbidden dump disposals on the basis of cost-distance analysis, search and investigate possible causes of soil, water and air pollution, investigate territories for indicating places for new waste dumps in overpopulated areas, etc. Due to the existence of several control mechanisms (EIONET reporting obligations, Basel convention etc.), functionality of the service is suitable also for cross-border users. More information about Pilot 3 is available on: Pilot 3: http://hlandata.sazp.sk/ (see Fig.4).

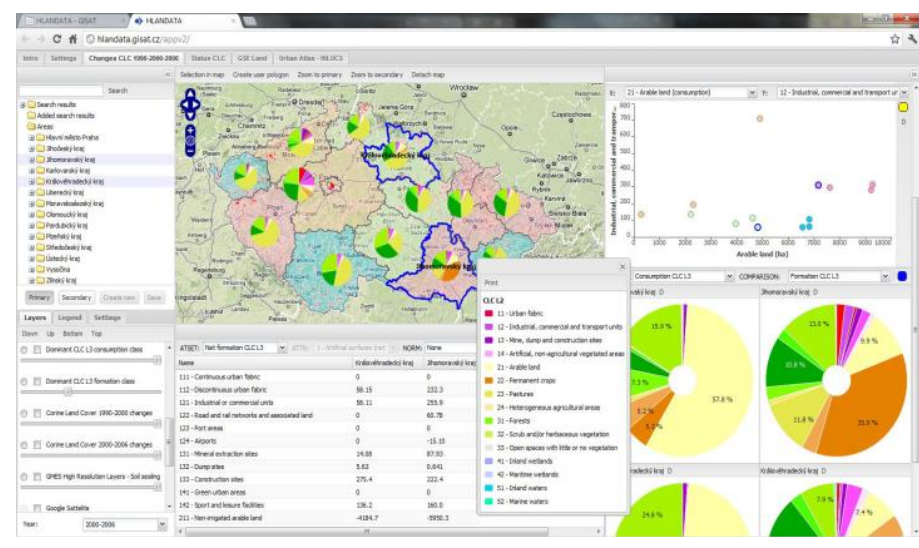

Fig 4: Example of the HLANDATA Pilots 3 - web tool interface

\section{THE E-LEARNING TOOL}

The e-learning framework was used within the HLanData project. The HLanData Training Platform was a part of Pilot 1 , but had been used also for other pilot projects. This tool was developed at the Institute of Mathematics and Computer Science and used for other EU projects like SDI-EDU and NaturNet lus $(\mathrm{NN}+)$ to support e-learning about GIS and INSPIRE.

The e-learning platform is an open source web browser based e-conference, collaboration and learning tool which supports slide shows, webpage demonstration, synchronous prerecorded video display, chat and lecturer live narration using web camera provided video and audio. Educational contents are described using meta-data and stored in a meta-data catalog to increase data accessibility. The training modules are structured with regard to HLanData project aims, themes (LC and LU), pilot projects and geoportal. Registration is required for users to access the training modules.

The HLanData Training Platform also links to the BRISEIDE Training Framework and HABITATS Networking Services and service toolkits. An introduction to other GIS harmonization activities across Europe (GMES, Humbolt, Plan4all etc.) is also provided to users. The e-learning tool is cloud-based and available for users at: http://hlandata.cloudlearning (see Fig. 5).

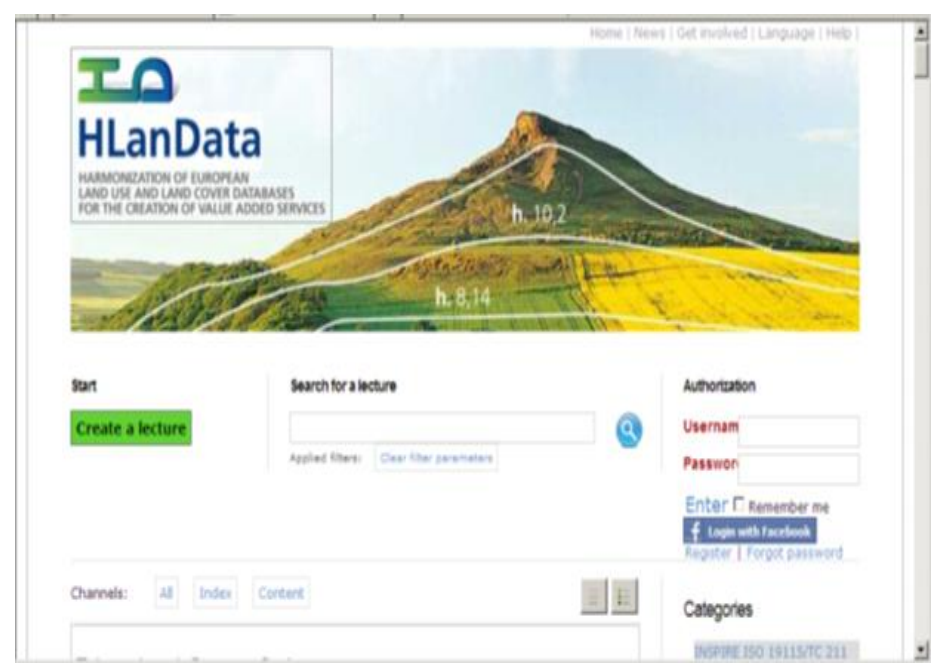

Fig 5: HLanData E-learning platform

\section{CONCLUTIONS}

HLanData project revealed that INSPIRE principles can be achieved and represents a real and massive application of the directive by trans-boundary public administrations and private enterprises with competence in geospatial data across Europe. Web-based applications and services provided by the project Pilots and Geoportal are fully operational and demonstrate the power of modern technological solutions to support the provision of complex spatial data sets (like a LC and LU) to the end user. Institutional users from central and local administration currently are the most stable demand for integrated web-based solutions providing harmonised LU/LC information, but there is a clear potential for expanding such services into the sector of higher education, the general public, as well as to develop business models. Barriers to implementation of INSPIRE are based on local traditions in data collection, quality of data sets and the precariousness of funding for implementing INSPIRE measurements in member states. At the same time the potential added value of spatial data is very high due to modern trends in how information is consumed and depicted in daily life. 


\section{\$ \&. $12: /(' * 0$ ( 17 ]}

The authors of the paper would thank The HLanData project team, especially Ms. Inga Berzina, project coordinator from Technical Development Forum of Latvia for contribution regarding valuable information about practical validation of the Pilot projects) and professor Ineta Geipele from Riga Technical University, The Faculty of Engineering Economics and Management.- for support and advice in the preparation of the paper.

\section{REFERENCES}

[1] Haines-Young, R., and Weber, J.-L. - 'Land Accounts for Europe 19902000. Towards Integrated Land and Ecosystem Accounting, Europen Environment Agency, 2006

[2] D1.1. Diagnostic Report. Accessible online: http://www.hlandata.eu/results.html

[3] D5.5. Communication and Dissemination Final Report. Accessible online: http://www.hlandata.eu/results.html

[4] D6.4 HLanData Final Technical Report. Accesible online: http://www.hlandata.eu/results.html

[5] I.Berzina: The Zemgale Planning Region Geoportal - Experience for Rural Development. In: Scientific Jornal of Riga Technical University. 14. Issue, Sustainable Development, Vol.2, pp. 72.-80. Riga, 2011.

[6] INSPIRE D2.3 Drafting team data specifications. Definition of Annex themes and scope. http://inspire.jrc.ec.europa.eu/reports/ImplementingRules/DataSpecificat ions/D2.3_Definition_of_Annex_Themes_and_scope_v3.0.pdf (last accessed in May 2013)
[7] Land Accounts for Europe 1990-2000. Towards Integrated Land and Ecosystem Accounting, EEA Report 11, Copenhagen, European Environment Agency. 2006

[8] K.Charvat, M.Alberts, S.Horakova. INSPIRE, GMES and GEOSS Activities, Methods and Tools towards a Single Information Space in Europe for the Environment, Riga, 2009, pp.4-29,

[9] Regulation (Eu) No 911/2010 Of The European Parliament And Of The Council of 22 September 2010 on the European Earth monitoring programme (GMES) and its initial operations (2011 to 2013), Official Journal of the European Union, L276/1. 20.10.2010, Brussels 2010

[10] Source: Drafting Team "Data Specifications" Definitions of Annex Themes and Scope:

[11] http://inspire.jrc.ec.europa.eu/reports/ImplementingRules/DataSpecificat ions/D2.3_Definition_of_Annex_Themes_and_scope_v3.0.pdf (last accessed in May, 2013)

[12] Source: http://ec.europa.eu/information_society/activities/ict_psp/index_en.htm (last accessed in May, 2013)

[13] Source: http://inspire.jrc.ec.europa.eu/reports/ImplementingRules/DataSpecificat ions (last accessed in May, 2013)

[14] Source: http://inspire.jrc.ec.europa.eu/index.cfm/pageid/48 (last accessed in May, 2013)

[15] Source: http://hlandata.sazp.sk/Templates/UI/Views/Text.aspx?page=928 (last accessed in May, 2013)

[16] Source: http://www.umweltdaten.de/publikationen/fpdf-1/2698.pdf (last accessed in May, 2013)

[17] P. Wyatt, M.Ralphs. GIS in Land and Property Management, 2003, p. 174 .

\section{Creative Commons Attribution License 4.0 (Attribution 4.0 International, CC BY 4.0)}

This article is published under the terms of the Creative Commons Attribution License 4.0

https://creativecommons.org/licenses/by/4.0/deed.en_US 